\title{
Anticorrosive Properties of Chitosan for the Acid Corrosion of Aluminium
}

\author{
B.A. Abd-El-Nabey, ${ }^{a}$ Y.M. Goher, ${ }^{b}$ H.A. Fetouh ${ }^{a,}{ }^{*}$ and M.S. Karam ${ }^{a}$ \\ ${ }^{a}$ Department of Chemistry, Faculty of Science, Alexandria University, Ibrahimia, \\ P.O. Box 426, Alexandria 21321, Egypt \\ ${ }^{b}$ Department of Botany, Faculty of Science, Alexandria University, Ibrahimia, \\ P.O. Box 426, Alexandria 21321, Egypt
}

\begin{abstract}
Potentiodynamic polarization and electrochemical impedance spectroscopy (EIS) techniques were used to measure the corrosion rate of aluminium in $0.1 \mathrm{M} \mathrm{HCl}$ in the absence and presence of different concentrations of chitosan. Inhibition efficiency up to $90 \%$ in the presence of $0.028 \mathrm{~g} / \mathrm{L}$ chitosan was achieved. Increasing the concentration of chitosan shifted the breakdown potential, $\mathrm{E}_{\mathrm{b}}$, of aluminium to more noble values and inhbitied the pitting corrosion of aluminium. Measurements of the break potential, $\mathrm{E}_{\mathrm{b}}$, and the electrical double layer capacity $\left(\mathrm{Q}_{\mathrm{dl}}\right)$ indicated that chitosan is adsorbed at the aluminium/solution interface.
\end{abstract}

Keywords: aluminium, polarization curves, pitting corrosion, Electrochemical Impedance Spectroscopy (EIS), charge transfer, adsorption.

\section{Introduction}

Aluminium was reported to be widely applied in aluminium-air technology, food industry and desalination plants. These industrial applications are due to the low density, favorable mechanical properties, good finishing, benign effect on the environment and the human health. The high corrosion resistance of aluminium is attributed to the natural surface protective oxide film. Aluminium suffers from pitting corrosion by chloride ion and many organic inhibitors are reported for the corrosion of aluminium in hydrochloric acid solutions [1-3].

Chitosan was reported to be used in the smart self-healing coating and as based polymer with 2-mercaptobenzothiazole anticorrosive coating for the aluminium

\footnotetext{
* Corresponding author. E-mail address: howida_fetouh@yahoo.com.
} 
alloy against the atmospheric corrosion $[4,5]$. Chitosan molecules are rich in hydroxyl and amino groups (Fig. 1), so it is a good potential inhibitor. El-Haddad [6] has investigated the inhibition characteristics of chitosan for the corrosion of copper in $0.5 \mathrm{M} \mathrm{HCl}$ using the potentiodynamic polarization and the electrochemical impedance spectroscopy (EIS) techniques. The polarization results indicated that chitosan acted as cathodic inhibitor and shifted the corrosion potential of copper from $\left(E_{\text {corr. }}=-94 \mathrm{mV}\right)$ into $\left(E_{\text {corr. }}=-174 \mathrm{mV}\right)$ for 0.5 $\mathrm{M} \mathrm{HCl}$ solution in the absence and prescence of $8 \times 10^{-6} \mathrm{M}$ chitosan respectively. The results also indicated that the inhibition efficiency of chitosan increased with increasing its concentration reaching the maximium value of $92 \%$ at the concentration of $8 \times 10^{-6} \mathrm{M}$ chitosan at $25^{\circ} \mathrm{C}$.

This work aims to study the electrochemical behavior and the inhibition effect of chitosan for corrosion of aluminium in $0.1 \mathrm{M} \mathrm{HCl}$ at $30^{\circ} \mathrm{C}$.

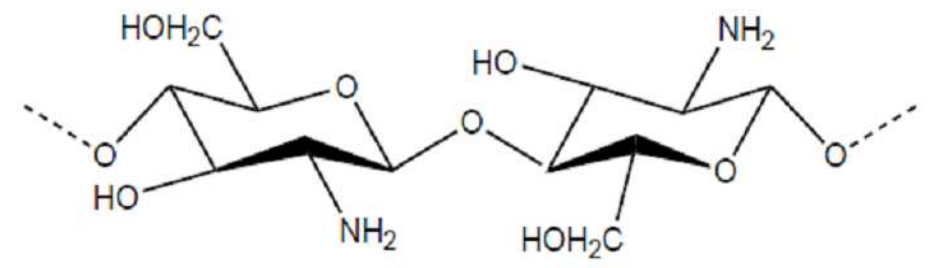

Figure 1. Chemical structure of chitosan.

\section{Experimental}

\section{Solution preparation}

Chitosan, that is a natural biopoymer, Fig. (1), was prepared in laboratory following the method reported elsewhere [7]. The structure of chitosan was elucidated by Infra red (IR) and UV-visible spectroscopy. Further characterization of chitosan was carried out by the determination of average number molecular weight and the degree of acetylation as reported previously[8]. Hydrochloric acid was purchased from Aldrich Chemicals Company. A stock solution of $1.0 \mathrm{M} \mathrm{HCl}$ solution was prepared using double distilled water. A stock solution of $0.1 \mathrm{~g} / \mathrm{L}$ chitosan was prepared in $10 \%$ acetic acid. The test solutions of $0.1 \mathrm{M} \mathrm{HCl}$ containing different concentrations of chitosan were prepared by appropriate dilutions.

\section{Electrochemical techniques}

The impedance measurements were achieved by applying an alternating potential (AC) signal of $10 \mathrm{mV}$ amplitude around the rest potential ( $E_{\text {rest }}$ ) to the electrode surface at the frequency range $\left(0.1 \mathrm{~Hz}-1.0 \times 10^{4} \mathrm{~Hz}\right)$. The data indicate that 88 reading points were recorded per decade.

The polarization curves were recorded by polarizing the aluminium electrode surface at a scan rate of $0.5 \mathrm{mV} / \mathrm{sec}$ of direct current (DC) starting from $-250 \mathrm{mV}$ below the rest potential, $E_{\text {rest }}$ to $+250 \mathrm{mV}$ above $E_{\text {rest }}$.

The working electrode was the aluminium sample of the following chemical composition: $0.37 \mathrm{C}, 0.212 \mathrm{Si}, 0.002 \mathrm{Mn}, 0.007 \mathrm{Cu}, 0.001 \mathrm{Mg}, 0.008 \mathrm{Zn}, 0.007$ Ti, 0.089 Fe, $0.004 \mathrm{~Pb}, 0.003 \mathrm{~B}, 0.001 \mathrm{Zr}, 0.0004 \mathrm{~V}, 0.0002 \mathrm{Cd}, 0.002 \mathrm{Gu}$, 
$0.0003 \mathrm{Ag}, \mathrm{Al}$ (98.64). The aluminium sample was fixed in a Teflon rod in such a way that only one surface area $\left(1.227 \mathrm{~cm}^{2}\right)$ was exposed to the test solution. This area was mechanically polished with emery papers of 320, 600 and 1000 grades, washed thoroughly with double distilled water then with absolute ethanol. The working electrode was introduced in the electochemical cell containing the reference saturated calomel electrode, the counter platinium electrode and $25 \mathrm{~mL}$ of the tested solution. The cell was thermostated at $30{ }^{\circ} \mathrm{C}$ for $20 \mathrm{~min}$ before starting the experiment, then connected to Gill AC-potentiostat that forced alternating or direct potential to the working electrode, then recording the current signal. The open circuit or the rest potential of the working electrode was followed as a function of time until steady state potential (equilibrium potential at which the variation of potential is $1.0 \mathrm{mV} / \mathrm{min}$.) was established to ensure reliable measurements in polarization and impedance measurements in aerated unstirred solutions [9].

\section{Results and discussion}

\section{Characterization of the structure of chitosan}

The chemical structure of the natural polymer that is shown in Fig. 1 was confirmed by various tools. Infrared spectroscopy, that is a measurement of intensity of the absorption of infrared (IR) radiation by a sample of chitosan at different wave numbers $\left(\mathrm{cm}^{-1}\right)$. The IR spectrum gave a characteristic band at $3450 \mathrm{~cm}^{-1}$ due to the stretching vibrations of $\mathrm{NH}_{2}$ and $\mathrm{OH}$ groups and another band at $2925 \mathrm{~cm}^{-1}$ that is a characteristic of $\mathrm{CH}_{2}(\mathrm{~s})$ symmetric vibrations.

Chitosan showed a broad absorption peak at the wavelength $(\lambda)$ of $425 \mathrm{~nm}$ in the UV-visible range of electromagnetic radiations. This peak corresponds to the electronic transition $\left(n-\sigma^{*}\right)$ of the free electrons in chitosan molecules [4].

The number of average molecular weight, $\overline{M_{n}}$ of chitosan molecules was determined by the colligative properties methods and was found to be nearly 24 kilo Dalton. Another evidence of the structure of chitosan is the degree of deacetylation of chitin (the precurser of chitosan). The deacetylation process of chitin was carried out by adding $50 \% \mathrm{NaOH}$ and then boiled at $100{ }^{\circ} \mathrm{C}$ for 2 hours on a hot plate. The samples are then placed under the hood and cooled for $30 \mathrm{~min}$ at the room temperature. Then the samples are washed continuously with $50 \% \mathrm{NaOH}$ and filtered in order to retain the solid chitosan. The samples were then left uncovered and oven dried at $110{ }^{\circ} \mathrm{C}$ for 6 hours [8]. The chitosan obtained will be in a creamy-white form. The degree of acetylation was achieved to be $85 \%$.

\section{Potentiodynamic polarization results}

Fig. 2 showed the potentiodynamic polarization curves for aluminium in $0.1 \mathrm{M}$ $\mathrm{HCl}$ in the absence and presence of different concentrations of chitosan. Increasing the concentration of chitosan shifted the corrosion potential, $\mathrm{E}_{\text {corr. }}$ to more noble values and retarded the anodic and the cathodic reactions indicating that chitosan is a mixed-type inhibitor [9]. At highly cathodic overvoltages, the current density continuously increases. The highly anodic overvoltage causes 
breakdown of the oxide film by chloride ion that replaced the adsorbed oxygen gas in some defect points at the breakdown potential, $\mathrm{E}_{\mathrm{b}}$ and the current density increases quickly.

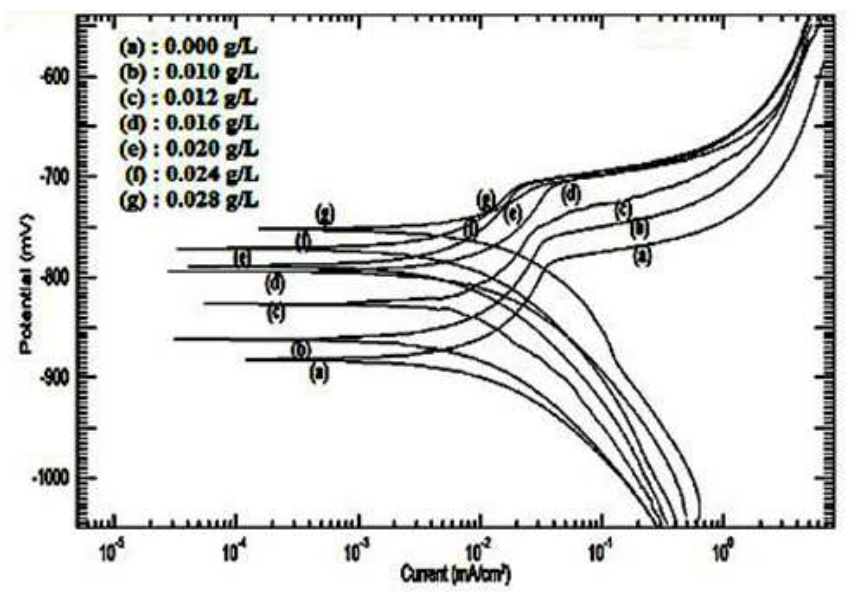

Figure 2. Potentiodynamic polarization curves for aluminium in $0.1 \mathrm{M} \mathrm{HCl}$ in the absence and presence of different concentrations of chitosan.

Table 1. Electrochemical polarization parameters of aluminium corrosion in $0.1 \mathrm{M} \mathrm{HCl}$ in the absence and presence of different concentrations of chitosan.

\begin{tabular}{ccccccc}
\hline $\begin{array}{c}\text { Chitosan] } \\
\mathbf{g} / \mathbf{L}\end{array}$ & $\begin{array}{c}-\mathbf{E}_{\text {corr }} \\
(\mathbf{m V})\end{array}$ & $\begin{array}{c}\boldsymbol{\beta}_{\mathbf{a}} \\
(\mathbf{m V . d e c a d e - 1 )})\end{array}$ & $\begin{array}{c}\mathbf{- \beta c} \\
(\mathbf{m V . d e c a d e - 1 )}\end{array}$ & $\begin{array}{c}\text { icorr } \\
(\mathbf{m A . c m}-\mathbf{2})\end{array}$ & $\mathbf{\% P}$ & $\begin{array}{c}-\mathbf{E b} \\
(\mathbf{m V})\end{array}$ \\
0.000 & 874.3 & 164.65 & 111.67 & 0.11369 & 0.0 & 801 \\
0.010 & 865.5 & 136.1 & 109.8 & 0.04713 & 58.6 & 745 \\
0.012 & 820.1 & 131.9 & 102.2 & 0.03511 & 69.1 & 725 \\
0.016 & 799.3 & 122.9 & 120.1 & 0.02213 & 80.5 & 700 \\
0.020 & 784.8 & 124.2 & 107.8 & 0.01518 & 86.6 & 690 \\
0.024 & 782.2 & 118.2 & 110.3 & 0.01317 & 88.4 & 688 \\
0.028 & 754.5 & 104.2 & 109.5 & 0.01218 & 89.3 & 687 \\
\hline
\end{tabular}

The anodic polarization curves showed an inflection (breakdown potential, $\mathrm{E}_{\mathrm{b}}$ ) corresponding to the pitting corrosion of aluminium. The breakdown potential was shifted to more noble values when chitosan is added, indicating retardation of pitting corrosion [10]. Applying Tafel extrapolation method on the cathodic and anodic Tafel lines gives the values of polarization parameters, including the corrosion potential, $\mathrm{E}_{\text {corr }}$, the corrosion current density, $\mathrm{i}_{\text {corr }}$, and the anodic and cathodic Tafel slopes, $\beta_{\mathrm{a}}, \beta_{\mathrm{c}}$ respectively, Table 1 .

The slope of the cathodic Tafel line $\left(\beta_{c}\right)$ remains nearly constant upon the addition of chitosan, indicating that the cathodic reaction which is the reduction of the hydrogen ion is not affected by the presence of chitosan and this step is charge transfer controlled. On the other hand, the slope of the anodic Tafel line $\left(\beta_{\mathrm{a}}\right)$ decreases by increasing the concentration of chitosan and largely decreases in the presence of high concentration of chitosan. This behavior indicated that the oxidation of aluiminium in the absence and presence of small concentrations of chitosan is charge transfer controlled and Tafel equation is applied. While, in the 
presence of higher concentrations of chitosan, the oxidation of aluminium is controlled by pitting corrosion and Tafel equation is not applicable [11].

\section{Electrochemical Impedance Spectroscopy (EIS) results}

The impedance plots of aluminium as Nyquist plots and the equivalent circuit model fit well the impedance spectrum with a small error and are represented in Fig. 3 (a, b). The Nyquist plots showed one capacitive semi-circle at high frequency region for all the examined solutions. These capacitive semi-circles indicate that the aluminium dissolution is mainly controlled by charge transfer process across the aluminium/solution interface. This capacitive loop is related to the dielectric properties of the oxide film $[12,13]$.

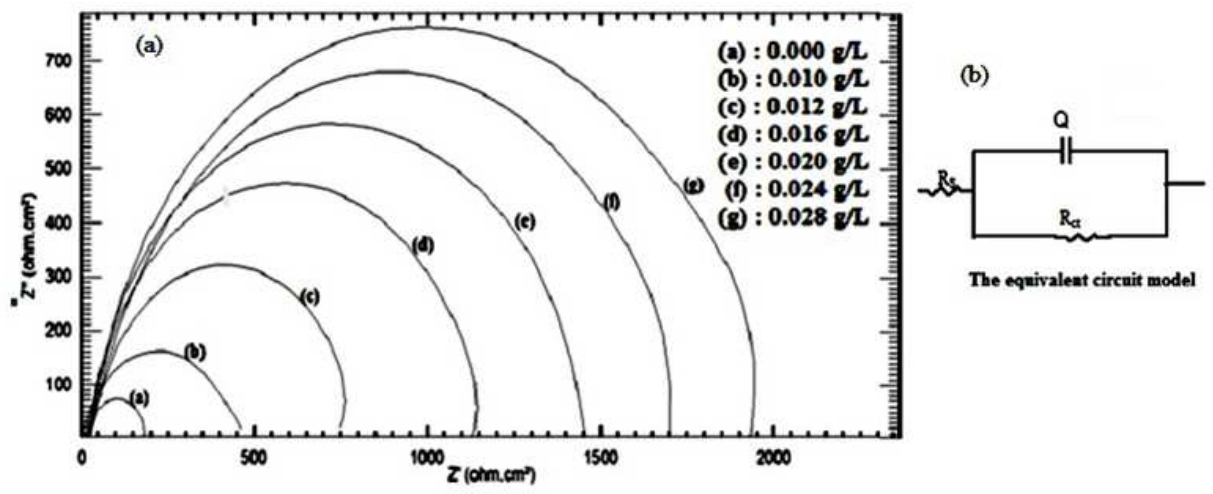

Figure 3. (a) Nyquist plots for aluminium in $\mathrm{HCl}$ in the absence and presence of different concentrations of chitosan and the theoretical equivalent circuit model.(b) The equivalent circuit model.

The Bode magnitude plots for aluminium in $0.1 \mathrm{M} \mathrm{HCl}$ at $30{ }^{\circ} \mathrm{C}$ in the absence and presence of different concentrations of chitosan are shown in Fig. 4. The Bode plots explain the impedance at the high frequency region. The simulated spectra of these plots indicated that the impedance increased with increasing the concentration of chitosan. The straight line obtained in Bode plots has a slope less than -0.5 indicating that the corrosion reaction is controlled by charge transfer, as predicted from Nyquist plots [14].

The diameter of the semicircle in the Nyquist plots increased with increasing the concentration of chitosan. The impedance parameters including the solution resistance $\left(R_{s}\right)$, the charge transfer resistance, $R_{c t}$, and the capacitance of the double layer $\left(\mathrm{Q}_{\mathrm{dl}}\right)$, are collected in Table (2).

The surface coverage $(\theta)$ of chitosan was calculated using the relations [9]:

$$
\theta=\frac{i_{0-1}}{i_{0}}=\frac{R_{c t-R_{c t o}}}{R_{c t}}
$$

where $i_{o}$ and $R_{c t o}$, and $I$ and $R_{c t}$, are the current density and the charge transfer resistance in the absence and presence of different concentrations of chitosan, respectively. 


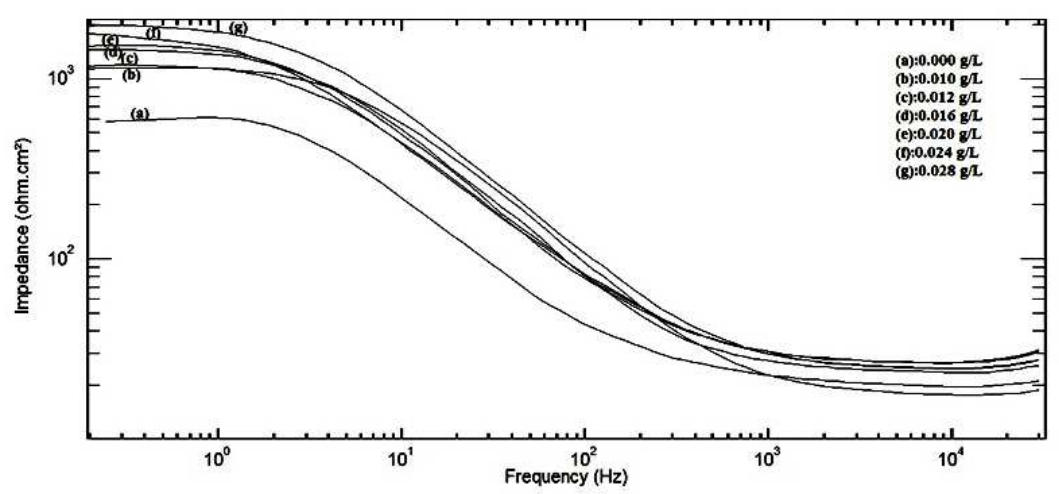

Figure 4. The Bode magnitude plots for aluminium in $0.1 \mathrm{M} \mathrm{HCl}$ at $30{ }^{\circ} \mathrm{C}$ in the absence and presence of different concentrations of chitosan.

Table 2. Electrochemical impedance parameters of aluminium corrosion in $0.1 \mathrm{M} \mathrm{HCl}$ in the absence and presence of different concentrations of chitosan

\begin{tabular}{cccccc}
\hline $\begin{array}{c}\text { Chitosan } \\
\mathbf{g} / \mathbf{L}\end{array}$ & $\begin{array}{c}\mathbf{R s} \\
\left(\mathbf{O h m . c m}^{\mathbf{2}}\right)\end{array}$ & $\begin{array}{c}\mathbf{Q d l} \\
\left(\boldsymbol{\mu} \mathbf{F} / \mathbf{c m}^{2}\right)\end{array}$ & $\mathbf{n}$ & $\begin{array}{c}\mathbf{R c t} \\
\left(\mathbf{O h m . c m}^{2}\right)\end{array}$ & \% $\mathbf{P}$ \\
\hline 0.0000 & 0.9 & 185.9 & 0.86 & 182.8 & 0.00 \\
0.002 & 2.24 & 167.7 & 0.88 & 211.2 & 13.4 \\
0.004 & 1.98 & 190.8 & 0.85 & 264.7 & 30.9 \\
0.006 & 2.11 & 87.1 & 0.88 & 310.0 & 41.0 \\
0.008 & 1.5 & 168.2 & 0.87 & 377.0 & 51.5 \\
0.010 & 1.2 & 178.2 & 0.87 & 450.0 & 59.6 \\
0.012 & 1.99 & 88.1 & 0.94 & 622.9 & 70.9 \\
0.016 & 2.76 & 54.4 & 0.87 & 1094.0 & 83.3 \\
0.020 & 2.39 & 45.11 & 0.87 & 1440.0 & 87.3 \\
0.024 & 2.5 & 61.3 & 0.84 & 1751.0 & 89.6 \\
0.028 & 2.6 & 40.1 & 0.84 & 1944.0 & 90.6 \\
\hline
\end{tabular}

The protection efficiency $\% \mathrm{P}=\theta \times 100$ in Tables 1 and 2 indicated that there is a fairly agreement between the results of polarization and the impedance measurements.

The dependence of the inhibition efficiency on the concentration of chitosan is shown in Fig. 5. The rapid linear increase of $(\% \mathrm{P})$ followed by steadily rising part indicates the formation of a monomolecular film of chitosan on aluminium surface [15].

\section{Statistical linear regression analysis of the results}

The statistical analysis of variance (Anova) method was used to analyze the significance of the influence of chitosan concentration on the thermodynamic (break down potential, $\mathrm{E}_{\mathrm{b}}$ ), and on the kinetic factors (corrosion current density

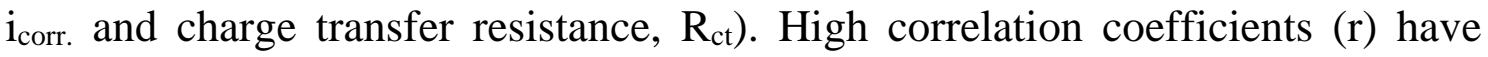
been obtained and indicated a strong relationship between the concentration of chitosan and the experimental variables $i_{\text {corr. }}, R_{c t}$ and $E_{b}$, as shown in Table 3 . 


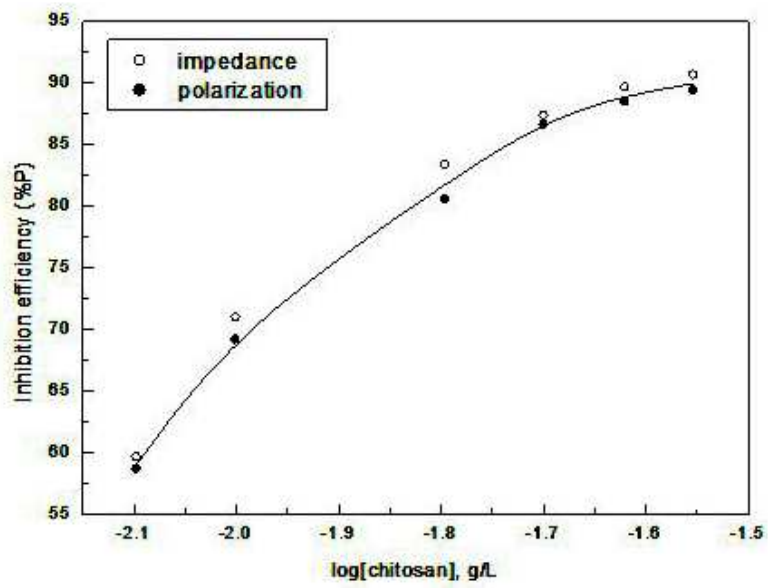

Figure 5. Variation of the inhibition efficiciency with the concentration of chitosan at $30{ }^{\circ} \mathrm{C}$.

Table 3. Analysis of variance (Anova) of the experimental variables of aluminium corrosion in $0.1 \mathrm{M} \mathrm{HCl}$ at the different concentrations of chitosan.

\begin{tabular}{cccc} 
[chitosan] $\mathbf{g} / \mathbf{L}$ & $\begin{array}{c}\text { icorr. } \\
\left(\mathbf{m A . c m} \mathbf{- n}^{-2}\right)\end{array}$ & $\mathbf{E b}(\mathbf{m V})$ & $\begin{array}{c}\text { Rct } \\
\left(\mathbf{O h m . c m}^{\mathbf{2}}\right)\end{array}$ \\
\hline $\begin{array}{c}\text { coefficient }(\mathbf{r}) \\
\text { to the variable }\end{array}$ & 0.91 & 0.94 & 0.98 \\
\end{tabular}

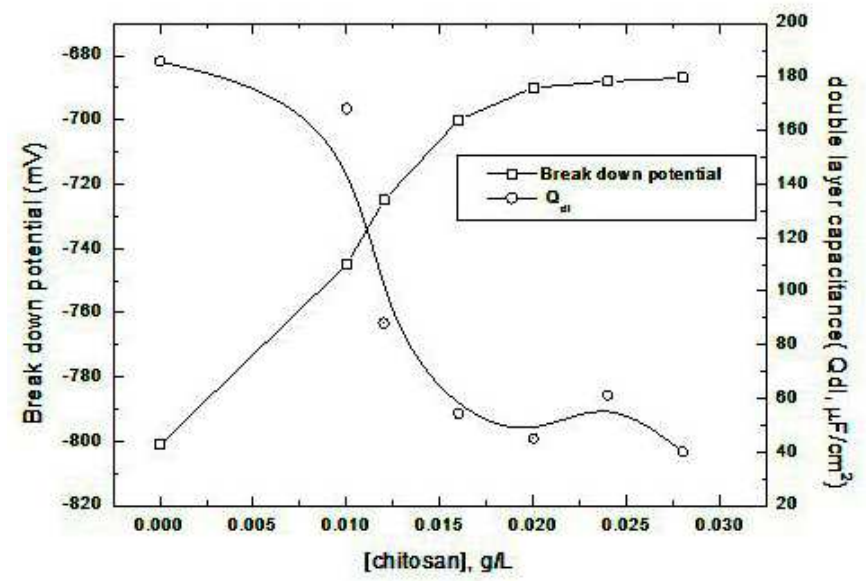

Figure 6. The variation of the breakdown potential, $\mathrm{E}_{\mathrm{b}}$, and the double layercapacitance, $\mathrm{Q}_{\mathrm{dl}}$, with the concentration of chitosan at $30^{\circ} \mathrm{C}$.

\section{Anticorrosive action of chitosan}

The pitting corrosion of aluminium occured near copper and iron containing intermetallic particles. Both $\mathrm{Cu}$ and $\mathrm{Fe}$ are more cathodic than aluminium matrix resulting in galvanic interaction [16]. Fig. (6) presents the variation of each of the breakdown potential $\left(\mathrm{E}_{\mathrm{b}}\right)$ and the double layer capacitance $\left(\mathrm{Q}_{\mathrm{dl}}\right)$ of aluminium in $0.1 \mathrm{M} \mathrm{HCl}$ with the concentration of chitosan. It is clear that the increase of the concentration of chitosan leads to the shift of the breakdown potential towards more anodic values, while the capacitance of the double layer decreases. A maximum shift in the breakdown potential is attained at $0.02 \mathrm{~g} / \mathrm{L}$ chitosan, the same concentration at which the double layer capacity has the minimum value. 
This behavior leads to the suggestion that $0.02 \mathrm{~g} / \mathrm{L}$ chitosan is the concentration at which the adsorbed monolayer is completely formed at the aluminium surface and the repesentative mode of adsorption is shown in Fig. (7).

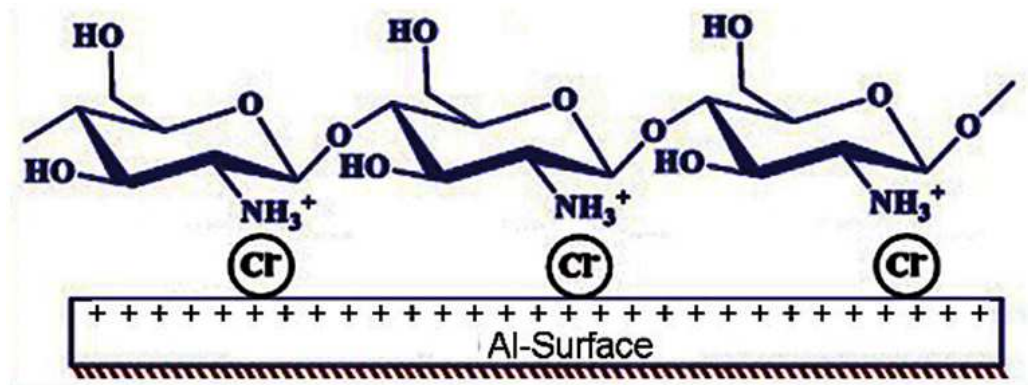

Figure 7. The mode of adsorption of chitosan on aluminium surface.

\section{Conclusion}

1) Increasing the concentration of chitosan shifted both the corrosion potential ( $\left.E_{\text {corr. }}\right)$ and the breakdown potential $\left(\mathrm{E}_{\mathrm{b}}\right)$ of the aluminium in $0.1 \mathrm{M} \mathrm{HCl}$ to more noble values and retarded both the anodic and the cathodic reactions, indicating that chitosan is a mixed-type inhibitor.

2) Oxidation of aluminium in $0.1 \mathrm{M} \mathrm{HCl}$ in the absence and presence of small concentrations of chitosan is charge transfer controlled and Tafel equation is applied, while in the presence of higher concentrations of chitosan, oxidation of aluminium is controlled by pitting corrosion and Tafel equation is not applicable.

3) The increase of the concentration of chitosan leads to the decrease of the electrical double layer capacity at the aluminium/solution interface in $0.1 \mathrm{M}$ $\mathrm{HCl}$ solution and shifted the breakdown potential towards more noble values. A maximum shift in the breakdown potential is attained at $0.02 \mathrm{~g} / \mathrm{L}$ chitosan, and at the same concentration the double layer capacity has the minimum value. This concentration is required to form an adsorbed monolayer of chitosan at the aluminium/solution interface.

4) Chitosan inhibits the pitting corrosion of aluminium in $0.1 \mathrm{M} \mathrm{HCl}$ with efficiency up to $90 \%$ at $0.028 \mathrm{~g} / \mathrm{L}$ and acts by adsorption at the aluminium/solution interface.

\section{References}

1. Şafak S, Duran B, Yurt A, et al. Corrosion Sci. 2012;54:251.

2. Fares MM, Maayta AK, Al-Qudah MM. Corrosion Sci. 2012;60:112.

3. Abd El Aal EE, Abd El Wanees S, Farouk A, et al. Corrosion Sci. 2013;68:14.

4. Yasakau KA, Tedim J, Zheludkevich ML, et al. Handbook of Smart Coatings for Materials Protection. 2014. P. 451-459.

5. Carneiro J, Tedim J, Fernandes SCM, et al. Surf Coat Technol. 2013;226:51. 
6. El-Haddad MN. Int J Biolog Macromol. 2013;55:142.

7. Islama MM, Masumb SM, Rahmana MM, et al. Int J Basic Appl Sci. 2011;11:77.

8. Hussain MR, Iman M, Maji TK. Int J Adv Eng Appl. 2013;6:4.

9. Abdel-Gaber AM, Abd-El-Nabey BA, Saadawy M. Corrosion Sci. 2009;51:1038.

10. Williams G, Coleman AJ, McMurray HN. Electrochim Acta. 2010;55:5947.

11. Kelly GR, John RS, David WS, et al. Electrochemical Techniques in Corrosion Science and Engineering. 2002.

12. Zhang QB, Hua YX. Mater Chem Phys. 2010;119:57.

13. Fetouh HA, Abdel-Fattah TM, El-Tantawy MS. Int J Electrochemical Sci. 2014;9:1565.

14. Lenderink HJW, Linden MVD, de Wit JHW. Electrochim Acta. 1993;38:1989.

15. Abd-El-Nabey BA, Abdel-Gaber AM, Elewady GY, et al. Int J Electrochem Sci. 2012;7:11718.

16. Meng Q, Frenkel GS. J Electrochem Soc. 2004;151:61. 